\title{
The Control of Insect Pests in Agriculture.
}

THE completion of the Ministry of Agriculture scheme for the appointment of advisory entomologists in each of the fourteen agricultural provinces of England and Wales has recently been fulfilled. By means of this organisation, the Phytopathological Branch of the Ministry is now enabled to keep in touch from year to year with most parts of the country with regard to the incidence of insect pests. Each advisory entomologist has his headquarters in a collegiate or university centre in his province, and his field of work lies in the diagnosis of injury due to insect pests on behalf of the farmers and growers of that area; he is further concerned with the dissemination of useful information on such subjects, and in the carrying out of experiments on the practical control of pests of local importance. At present the advisors' duties are therefore of a somewhat comprehensive character. As time goes on, it is reasonable to hope that as the county councils' staffs develop and extend their spheres of utility, they will be able to take on much of the purely advisory duties. In this way it should eventually be possible to free the advisor in order that he may be able to devote his inquiries more especially to the investigation of particular local problems.

The work of the advisors renders them in a position to forward to the Ministry annotated lists, or in some cases more detailed information, respecting the pests that come under their notice. There is also a considerable number of voluntary observers located in different parts of England and Wales who assist in a similar manner. The information thus garnered is collated and sifted in the Ministry's Pathological Laboratory at Harpenden. The present report ${ }^{1}$ is to a large extent a summary of the data collected by some sixty-two observers during the years I922-1924. It is the fifth of its series, but differs from its predecessors in that tabular lists of every recorded species of injurious insect are, very wisely, no longer included. Certain innovations in regard to pest control during the years under review are mentioned. Perhaps the most notable of these is the application of certain proprietary compounds, collectively known as " carbolineum," as washes for fruit trees. These compounds consist of various products obtained in the distillation of coal and are of variable composition. There appears to be no question as to the efficiency of certain of the "brands "bearing the name of carbolineum in the destruction of the resting eggs of aphids and apple sucker. It is important to know, however, whether such treatment can be carried out over successive years without injury to the trees; also, whether the manufacturing firms are able to give guarantees to the effect that materials which gave good results one year will remain purchasable with their original composition unaltered.

Among individual pests the raspberry beetle has always been troublesome to raspberry growers and has also become a menace to loganberry culture. Experiments carried out at the Long Ashton station show that it can be largely controlled by spraying the plants with lead arsenate when they are one-third, two-thirds, and fully in bloom. Apart from the possibility of poisoning trees, the market price of the fruit in relation to the costs of spraying will be the deciding factor for, or against, this method of treatment. The apple blossom weevil is another insect difficult to control, and this fact has attracted attention at the East Malling Research Station, where

I 1 "Report on the Occurrence of Insect Pests on Crops in England and No. 49, Ministry of Agriculture and Fisheries, ro25. Is. $6 d$. net. the respective values of different methods of repression have been tested over the period I92I-I924. The only method that proved of value was the trapping of the weevils by means of bands of sacking tied around the trunks of the trees. The hibernating weevils lay up in such material, which led to their capture in large numbers. Among other noteworthy measures, the application of lime-sulphur against the "big-bud" disease of black currants has given promise when applied at winter strength in March.

The control of vegetable root flies, which is occupying the attention of Mr. K. M. Smith at Manchester, appears to be best achieved by the use of odorous substances acting as deterrents, which protect the crop by keeping the insects away. One of the best of these preventives is stated to be anthracene oil absorbed in some powder carrier, such as powdered chalk. As the result of Lloyd's work at the Lea Valley Experiment Station at Cheshunt, on fumigation with tetrachlorethane, fumigants of this type have come into prominence in the case of White Fly attacks on plants under glass. The application of tetrachlorethane is more expensive than that of hydrocyanic acid gas, but it is a less poisonous remedy for operatives to handle and, in the case of tomatoes, it is no longer necessary to dry off the house prior to treatment in order to avoid injury.

The British Isles have up to the present suffered very little from the attacks of imported agricultural pests. The factors contributing to this situation are not easy to discover, but the absence of extensive areas of country devoted to single-crop cultivation, together with the practice of crop rotation, afford conditions on the whole unfavourable to the establishment of immigrant form.s. Furthermore, a variable and, on the whole, inclement climate is probably an important barrier to most species which are denizens of warmer regions. Legislation also serves to keep down the number of alien species which reach this country. On the other hand, sundry foreign insects do succeed in gaining entry and, unless track is kept of them, it is possible that one or other kind may succeed in gaining a permanent foothold. During the period covered by the present report several of such species are specially mentioned. The most important of these is the Potato Moth (Phthorimaea operculella Zell.), which has been detected by the Ministry's inspectors in consignments of potatoes imported from Malta and the Canary Isles. Since it is an insect with considerable power of adaptation to climatic conditions, the destruction, or re-exportation, of such consignments is a very necessary measure. Among other interceptions, larvæ of a beetle of the genus Brachycerus have occurred in consignments of snowdrop bulbs from Smyrna; beans affected by the American Bean Beetle (Bruchus obtectus Say.) from Minnesota; and peaches from $\mathrm{S}$. Africa infested with larva of the Mediterranean Fruit Fly (Ceratitis capitata Wied.).

The outstanding features during the period under review were: (I) the damage occasioned by Fruit Fly and to a lesser degree by Gout Fly in 1922 , (2) severe outbreaks of aphids and caterpillars in orchards in I923, (3) a remarkable absence of most epidemic pests in 1924. In each case the phenomenon observed appears to be largely fostered by the prevailing weather conditions during the seasons concerned, but, until we are in a position to correlate a larger number of years' observations between weather and fluctuations of pest epidemics, such conclusions are necessarily somewhat speculative.

Several indigenous species of insects are, for the first

NO. 2937, VOL. I I 7 ] 
time, recorded as injuring crops in England and Wales. These include the fly Chortophila sepia Mg. which did considerable damage to wheat in Cambridgeshire; barley and other cereals in Kent were attacked by the small acalypterate fly, Diplotoxa limbata Meig.; old potato sets in $\mathrm{N}$. Wales were infested by a little-known Coccid, Pseudococcus gahani Green; in widely separated localities beans suffered from the attacks of several species of root flies of the genus Chortophila and, in
Norfolk, the Dock Saw Fly (Taxonus glabratus) occasioned considerable injury to apples.

Mr. J. C. F. Fryer, the Director of the Ministry's Pathological Laboratory, has produced a report which summarises the activities of his charge in a concise and readable form. The value of documents of this character is usually not immediate, but it is rather that they place on permanent record information for the use of posterity.

\section{Recent Star Catalogues.}

A VERY interesting star catalogue has lately been published in the joint names of Prof. Frank Schlesinger and Ida Barney. It contains 8359 stars between N. Decl. $50^{\circ}$ and $55^{\circ}$, observed by photography at Allegheny Observatory between August $3 \mathrm{r}$, I9r 5 , and July $\mathrm{I}_{4}$, I9r6. The number of plates is ninety, their centres all being at Decl. $52 \frac{1}{2}^{\circ}$, and the Right Ascensions increasing by $16 \mathrm{~min}$, or $2.4^{\circ}$ of great circle. The measured portion of each plate is a square $5^{\circ} \times 5^{\circ}$ : each star appears on two plates; on one to the east of the centre, on the other to the west. The two plates are measured in reversed positions in the micrometer, so that all systematic "magnitude-equation " in R.A. should be eliminated. The object glass is a symmetrical doublet of four lenses, of aperture $\mathrm{IO}_{3} \mathrm{~mm}$., and equivalent focal length $\mathrm{x} \cdot 635^{5}$ metre, giving a scale of $126^{\circ} 2^{\prime \prime}=1 \mathrm{~mm}$. A circular stop ensures full illumination over the plate, but reduces the effective aperture to $75.5 \mathrm{~mm}$. Exposure of 25 minutes is found to give strong images to well below the ninth magnitude, except in the case of some red stars.

The places given are referred to those of 1070 stars in the zone, which were observed (each star twice) on the meridian by Prof. R. H. Tucker at Lick Observatory from February I9I7 to March I9I8. Their places for $1917^{\circ} 0$ are given as a supplement to this catalogue. Their average magnitude is $8 \cdot 5$, the same as that of the main catalogue. The latter is referred to the equinox of $I 875^{\circ}$, to facilitate comparison with the Harvard A.G. Catalogue of the same zone. This comparison gives determinations of proper motion of all the stars. They are printed to the third decimal of $\mathrm{I}^{\prime \prime}$, the probable error of each being about o.0I $5^{\prime \prime}$.

On plotting the "crude" proper motions in R.A. for the separate magnitudes and the separate hours of R.A., they form sine-curves the amplitudes of which steadily diminish for the fainter stars owing to greater distance, and the median lines of which get steadily lower. The latter result is due to "magnitude-equation " in the Harvard A.G. Catalogue. The values found for the latter increase from $0.039 \mathrm{~s}$. for magnitude 6.4 to $0.232 \mathrm{~s}$. for magnitude 9.7 ; these are applied in forming the printed proper motions.

It is welcome news that the zone from Decl. $2^{\circ}$ south to $2^{\circ}$ north, photographed about I9I 6 , will shortly be published, and that Prof. Schlesinger contemplates the production of similar catalogues for all the A.G. zones.

Volumes $\mathrm{I}$ and 2 of the Sydney Astrographic Catalogue have lately come to hand. They cover Decl. $5 \mathrm{I}^{\circ}$ to $53^{\circ}$ south, and R.A. $\mathrm{o}^{\mathrm{h}}$ to $6^{\mathrm{h}}$ and $6^{\mathrm{h}}$ to $12^{\mathrm{h}}$ respectively. Vol. 3 appeared earlier. It will need fifty-two volumes to cover the entire Sydney zone, which extends from $51^{\circ}$ to $65^{\circ}$ south. The $\mathrm{X}, \mathrm{Y}$ co-ordinates are printed to the third decimal of a reseau interval; the magnitudes are indicated by letters or numbers on two arbitrary scales; further information is needed to reduce these to the ordinary system. There are 280 stars on a fully printed page (but there are many gaps). Vol. I has 25 pages; vol. 2 (the galactic latitude of which is lower) 85 pages.

\section{Explorations in Borneo.}

THE fourteenth and fifteenth reports on the Sarawak Museum deal with the years I9I5 to I924. For most of this time it had no curator. Major J. C. Moulton left to join his regiment in February 19I5, and his successor, Dr. E. Mjöberg, did not take office until May 1922. He in turn left in December 1924 , and was succeeded in February 1925 by Mr. E. Banks. During his curatorship Dr. Mjöberg devoted his energies mainly to collecting, and these two reports give the chief results of his expeditions, of which the chief were those to Mt. Murud and Mt. Poi.

Mt. Murud had never been visited by a white man, and its precise position was in fact uncertain. It forms the most northern and highest point of the Pamabo Range, which here falls down into a deep valley, bounded by the east-west mountain range Batu Litan. Its height, estimated at ro,ooo feet, proves to be 7200 feet, with another peak of 7160 feet. The mountain is built of sandstone, and its slopes are exceedingly rough, full of caves, holes, and crevices, and covered with enormous boulders. The natural difficulties of travel were not lessened by the difficulty of obtaining carriers, owing to the prevalence of an epidemic, and by the inability of the Dyaks to stand the climate of the heights. Dr. Mjöberg slept for six nights alone on the top ridge, making a proper biological survey. He describes it as " a strange-looking alpine region, with scanty low bushes of leathery appearance, covered with the yellow blossoms of a little epiphytic orchid. Here and there patches of smaller pine trees were seen. Bright scarlet or white flowers of the rhododendron and similar plant types were met with everywhere. Gigantic pitcher-plants (Nepenthes) of strange shape and countless varieties of beautiful, flowering orchids, formed the more striking types of plant life. Only a single little yellow-breasted bird broke the silence of this unknown landscape, never before seen by human eye."

The pitcher-plants just mentioned were responsible for the abundance of a very small frog. In the absence of pools, these frogs lay their eggs in the pitchers, and being thus dependent on a minimum of water for passing through their larval stages, they cannot grow larger than one's thumb-nail.

Strong lanterns of $25^{\circ}$ candle-power were kept alight all night on the summit and attracted many curious moths and other insects. On the highest peak fresh tracks of the wild pig, Sus barbatus, were observed.

Descending to the plains of the Kalabit country, and along the Baram River, which was found to have 